\title{
Prática pedagógica em Laboratório de Informática Educativa antes da Pandemia: dificuldades, desafios e reflexões
}

Pedagogical practice in an Educational Informatics Laboratory before the Pandemic: difficulties, challenges and reflections

Práctica pedagógica en un Laboratorio de Informática Educativa ante la Pandemia: dificultades, desafíos y reflexiones

\section{Resumo}

As Tecnologias Digitais de Informação e Comunicação estão em todos os setores da sociedade, inclusive na Educação. Apesar disso, pesquisas têm indicado a dificuldade de os professores integrarem os recursos educacionais digitais em sua prática pedagógica. Neste sentido, este estudo apresenta uma discussão sobre a prática pedagógica dos professores de uma escola pública municipal da cidade de Fortaleza em relação a utilização da tecnologia, antes da pandemia. A pesquisa teve abordagem qualitativa, com estudo de natureza descritiva e explicativa. Analisamos a metodologia empregada e as dificuldades encontradas para ministrar aulas que empreguem recursos educacionais digitais, por meio de entrevistas semiestruturadas, questionários e observações de aulas presenciais. Os resultados apontam para a necessidade de um planejamento racionalizado e em conjunto com os professores, assim como a necessidade de formação continuada para esses profissionais, com a participação de comunidades de aprendizagem que privilegie a produção do conhecimento. Pesquisas futuras apontam para a necessidade de acompanhamento pedagógico para um apanhado qualitativo e quantitativo das práticas durante e pós-pandemia.

Palavras-chave: Recurso educacional digital; Prática pedagógica; Planejamento; Laboratório de informática.

\begin{abstract}
Digital Information and Communication Technologies are present in all sectors of society, including Education. Despite this, research has indicated the difficulty of teachers to integrate digital educational resources in their pedagogical practice. In this sense, this study presents a discussion about the pedagogical practice of teachers from a municipal public school in the city of Fortaleza in relation to the use of technology, before the pandemic. The research had a qualitative approach, with a descriptive and explanatory study. We analyzed the methodology used and the difficulties found to teach classes that use digital educational resources, through semi-structured interviews, questionnaires and classroom observations. The results point to the need for a rationalized planning in conjunction with teachers, as well as the need for continuing education for these professionals, with the participation of learning
\end{abstract}


communities that favor the production of knowledge. Future research points to the need for pedagogical monitoring for a qualitative and quantitative overview of practices during and after the pandemic.

Keywords: Digital educational resource; Pedagogical practice; Planning; Computer lab.

\begin{abstract}
Resumen
Las Tecnologías de la Información y las Comunicaciones Digitales están presentes en todos los sectores de la sociedad, incluida la Educación. A pesar de esto, la investigación ha señalado la dificultad de los docentes para integrar los recursos educativos digitales en su práctica pedagógica. En este sentido, este estudio presenta una discusión sobre la práctica pedagógica de los docentes de una escuela pública municipal de la ciudad de Fortaleza en relación al uso de la tecnología, antes de la pandemia. La investigación tuvo un enfoque cualitativo, con un estudio descriptivo y explicativo. Analizamos la metodología utilizada y las dificultades encontradas para impartir clases que utilizan recursos educativos digitales, a través de entrevistas semiestructuradas, cuestionarios y observaciones en el aula. Los resultados apuntan a la necesidad de una planificación racionalizada en conjunto con los docentes, así como la necesidad de una formación continua para estos profesionales, con la participación de comunidades de aprendizaje que favorezcan la producción de conocimiento. Las investigaciones futuras apuntan a la necesidad de un seguimiento pedagógico para una visión general cualitativa y cuantitativa de las prácticas durante y después de la pandemia.
\end{abstract}

Palabras clave: Recurso educativo digital; Práctica pedagógica; Planificación; Laboratorio de informática.

\title{
1. Introdução
}

Com a era das inovações tecnológicas, é possível constatar cada vez mais o uso das Tecnologias Digitais de Informação e Comunicação (TDIC) em atividades administrativas, nas práticas de ensino ou em outras tarefas escolares. Nos últimos anos foram desenvolvidos pelo Ministério da Educação em conjunto com as Secretarias Municipais e Estaduais de Educação alguns programas (EDUCOM, PROINFO, Mídias na Educação, TV Escola, Projeto UCA, Educação conectada). Esses programas tinham como objetivo inserir e apoiar a tecnologia na escola e contribuir para que os professores utilizem a tecnologia em sua prática pedagógica (Almeida, Almeida \& Fernandes-Júnior, 2018).

Desde o final da década de 1980, diversas escolas públicas de todo o Brasil começou a implantar laboratórios de informática, integrando e promovendo a aproximação dos alunos e professores às tecnologias digitais (Valente \& Almeida, 1997). Os computadores chegaram à escola modificando o cenário escolar, exigindo formação docente para criação de novas práticas pedagógicas utilizando recursos tecnológicos como forma de buscar produzir um ensino de qualidade.

A influência das TDIC na Educação reflete diretamente sobre o papel dos professores no novo contexto, sobre as novas formas de aprender e sobre a organização da própria escola como instituição social responsável pela Educação dos indivíduos (Kalinke \& Motta, 2019). Neste sentido, Almeida e Valente (2016, p. 37) defendem, que em relação às TDIC, os professores precisam ser "capazes de analisar por quê, para quê, com o quê, como e quando integrar esse conhecimento à prática pedagógica".

A prática pedagógica com as tecnologias digitais, como computador, internet e seus conteúdos necessitam de procedimentos indispensáveis à ação do professor. Para isso, é necessária uma prática reflexiva, uma mudança no papel do professor a partir da previsão de um planejamento e avaliação, correlacionando os conteúdos vistos em sala de aula com os conteúdos com as TDIC (Fagundes et al, 2005).

Neste sentido, Moran (2015, p. 4) explica que “(...) o que a tecnologia traz hoje é integração de todos os espaços e tempos. O ensinar e aprender acontece numa interligação simbiótica, profunda, constante entre o que chamamos mundo físico e mundo digital". O computador pode auxiliar e melhorar o que o professor faz em sala de aula, pois o uso de recursos digitais possibilita o aprendizado dos conteúdos curriculares, a partir da ampliação do potencial cognitivo do ser humano, mas para que isso aconteça os professores precisam saber como utilizar, pedagogicamente, esses recursos.

Apesar da significativa ampliação do parque tecnológico dos laboratórios de informática educativa, em grande parte das escolas públicas de todo o país, podemos observar a partir das práticas pedagógicas dos professores o uso limitado e na maioria das vezes conservador de suas potencialidades (Almeida, Almeida \& Fernandes Júnior, 2018). Para Kenski (2007, p. 
101), “... as TIC exigem transformações não apenas nas teorias educacionais, mas na própria ação educativa e na forma como a escola e toda a sociedade percebem sua função na atualidade".

Pesquisas com o uso de TDIC (Castro, 2016; Castro \& Castro-Filho, 2020; Prain \& Waldrip, 2006) têm revelado potencialidades, tais como o uso de múltiplas representações; simulações de situações reais; o trabalho em contextos investigativos; a produção de conteúdo e informação, dentre outras possibilidades. Apesar disso, devido a falta de formação e a disponibilização de infraestrutura adequada, muitas vezes, estas potencialidades são subutilizadas nas escolas brasileiras (Almeida, Almeida \& Fernandes-Júnior, 2018; Kalinke \& Motta, 2019).

Dentro dessa perspectiva, o objetivo da presente pesquisa é apresentar como os professores da sala de aula e do Laboratório de Informática Educativa (LIE) de uma escola pública municipal de Fortaleza têm utilizado as tecnologias digitais, antes da pandemia.

Nas sessões seguintes, discutiremos aspectos relevantes sobre o uso das tecnologias digitais na Educação e da prática pedagógica do professor. Em seguida, explicaremos a metodologia usada na pesquisa, seguida dos resultados e discussões do estudo. Ao final, as considerações finais do trabalho serão dispostas.

\section{Práticas Pedagógicas e as Tecnologias Digitais}

Vivemos um momento privilegiado propiciado pelas Tecnologias Digitais de Informação e Comunicação (TDIC), no qual o computador e suas várias aplicações é uma realidade em muitas escolas. O aproveitamento das potencialidades desse aparato tecnológico dependerá da ação do professor, ou seja, de sua prática pedagógica (Almeida, Lopes \& Braga, 2020).

A prática pedagógica expressa as atividades cotidianas que estão incluídas no cenário escolar com características diferentes e que dependem de uma série de fatores para se desenvolverem: as relações entre professores e alunos, metodologia, concepção de Educação e de escola. Como afirma Veiga (1992, p. 16) a prática pedagógica é “... uma prática social orientada por objetivos, finalidades e conhecimentos, inserida no contexto da prática social”, portanto, é o encontro das ações intencionadas dos educadores com as ações dos estudantes no contexto escolar.

Ao trabalho docente deve possibilitar componentes que auxiliem e orientem a prática pedagógica. Como requisito primordial para promover mudanças em relação a essa prática, o ato de avaliar, elaborar, planejar as atividades com a utilização de recursos digitais contribui para aprimorar o sentido de busca do objetivo educacional que não é meramente reprodução de conteúdo. É um processo que envolve reflexão e decisões sobre a organização, o funcionamento e a proposta pedagógica da instituição. Conforme Libâneo (1992, p. 221), "é um processo de racionalização, organização e coordenação da ação docente, articulando a atividade escolar e a problemática do contexto social".

O planejamento deve "ser concebido, assumido e vivenciado no cotidiano da prática social docente, como um processo de reflexão" (Fusari, 1989, p. 45). Portanto, tem como objetivo repensar, refletir, preparar, avaliar, possibilitando um melhor aproveitamento das atividades de forma que a apropriação do conhecimento ocorra via problematização e não simplesmente pela transmissão de conteúdo e resultando em uma melhor aprendizagem dos alunos.

Contudo a constituição do saber do professor tem tido poucos critérios para a análise de sua prática. Simião e Reali (2002) alertam sobre a necessidade de o professor atuar como pesquisador de recursos e atuar como um mediador atualizado, criativo, na concretização do projeto pedagógico pretendido. Para que o professor consiga identificar situações de uso adequado das tecnologias digitais é necessário que tenha algum tipo de letramento em termo de tecnologias de informação e comunicação, pois dessa forma terá condições de integrar o computador nas práticas pedagógicas (Coll, Mauri \& Onrubia, 2010; Castro \& Castro-Filho, 2012; 2020). 
Os Recursos Educacionais Digitais são ferramentas vistas como instrumento na prática pedagógica que possibilitam ao professor cumprir os objetivos propostos no seu planejamento, desde que sejam integrados adequadamente ao currículo escolar. A exemplo disso, a pesquisa de Castro e Castro-Filho (2020) apresenta um projeto desenvolvido com 12 estudantes do $6^{\circ}$ ano do Ensino Fundamental que integra as TDIC, a partir de um projeto denominado Pensar, Conectar e Fazer ${ }^{1}$.

A pesquisa tinha como objetivo analisar evidências do potencial das tecnologias ditais, para isso, utilizou-se de Recursos Educacionais Digitais, tais como: vídeos, softwares, simulações, aplicativos; como meio de promover a produção colaborativa de materiais, como vídeos, infográficos, textos argumentativos, dentre outros (Castro \& Castro-Filho, 2020). Os resultados trazem evidências de que as tecnologias contribuíram para a aprendizagem da Matemática, por meio da visualização e da representação, da construção e produção de conhecimento e da significação, possibilitadas pelas TDIC.

Neste sentido, o professor pode adotar em sua prática abordagens com viés construcionistas ou instrucionista. O Projeto desenvolvido na pesquisa de Castro e Castro-Filho (2020) é um exemplo do uso das TDIC no modelo construcionistas, ou seja, em que a tecnologia é utilizada como ferramenta que proporciona a simulação e prática de diversas situações de aprendizagem, possibilitando alunos e professores atuarem como sujeitos do processo de construção e reconstrução do conhecimento.

A abordagem instrucionista ainda está muito presente na escola, sendo o computador utilizado para fazer atividades sem reflexão, ou seja, como uso otimizado da máquina de ensinar (Papert, 2008).

Nessa perspectiva é importante discutirmos a prática pedagógica dos professores com relação ao uso das tecnologias, a partir de sua formação, planejamento e escolha dos recursos utilizados durante a aula. Na próxima seção serão explanados os procedimentos metodológicos da pesquisa.

\section{Procedimentos Metodológicos}

A presente pesquisa ocorreu em uma escola pública municipal de Fortaleza, cuja implantação do Laboratório de Informática Educativa (LIE) foi iniciada no ano de 2002 e que está em funcionamento até os dias atuais. A pesquisa foi realizada antes da pandemia causada pelo novo coronavírus, nesta época, o LIE dessa escola funcionava nos três turnos e tinha como responsáveis dois professores: um para o turno da manhã e outro para os turnos tarde e noite. Pretendemos focar nos dados obtidos a partir de entrevistas com o professor do LIE do turno da manhã e os professores de sala de aula que levavam suas turmas para desenvolverem algum tipo de atividade no laboratório.

A metodologia da pesquisa é de abordagem qualitativa com estudo de natureza descritiva e explicativa, na forma de estudo de caso, visto que pretendemos apresentar um conhecimento aprofundado da realidade em questão (Trivinõs, 1995).

Foram analisados três tipos de instrumentos: (1) Entrevista semiestruturada com o professor do LIE, (2) Entrevista estruturada com os professores de sala de aula e (3) Observações das aulas no Laboratório de Informática Educativa. As análises foram feitas por meio da Triangulação de destes dados.

Participaram da pesquisa: um professor do LIE, quatro professores pedagogos do Ensino Fundamental de $1^{\circ}$ ao $5^{\circ}$ ano. Para facilitar a leitura e análise dos dados denominamos o professor do LIE como PL, e os professores de sala de aula como PS, sendo os sujeitos diferenciados apenas pelo número, como forma de garantir seus anonimatos. Para maior compreensão dos sujeitos pesquisados e sua relação com as tecnologias educacionais, apresentamos o quadro 1.

\footnotetext{
${ }^{1}$ Disponível em: http://pensar-conectar-fazer.blogspot.com/
} 
Quadro 1 - Caracterização dos Professores: Formação Inicial, Ano de atuação, Formação na área de tecnologia, Tempo de docência e Experiência no LIE.

\begin{tabular}{|c|c|c|c|c|c|}
\hline Sujeitos & $\begin{array}{c}\text { Formação } \\
\text { Inicial }\end{array}$ & $\begin{array}{c}\text { Ano em que } \\
\text { atua }\end{array}$ & Formação (área de tecnologia) & Tempo de docência & Experiência no LIE \\
\hline PL & Pedagogia & Em todas & $\begin{array}{c}\text { Especialização em sistemas e } \\
\text { mídias digitais (UFC) } \\
\text { Em andamento }\end{array}$ & 12 anos & 8 anos \\
\hline PS1 & Pedagogia & $4^{\circ}$. Ano C & Não tem & 2 anos & Não tem \\
\hline PS2 & Pedagogia & $2^{\circ}$. Ano B & Não tem & 9 anos & Não tem \\
\hline PS3 & Pedagogia & $2^{\text {o. } \text { Ano C }}$ & Não tem & 1 ano & Não tem \\
\hline PS4 & Pedagogia & $3^{\circ}$. Ano C & Não tem & 3 anos & Não tem \\
\hline PS5 & Pedagogia & $5^{\circ}$. Ano A & Não tem & \\
\hline
\end{tabular}

Fonte: Autores, a partir dos dados coletados.

Na sequência trabalhamos com os resultados obtidos de forma que as respostas do professor do LIE e dos professores de sala de aula foram comparadas com as observações das aulas, possibilitando uma melhor compreensão da dinâmica do laboratório de informática da escola investigada.

\section{Resultados e Discussão}

A seguir serão apresentados e discutidos os dados coletados, a partir de quatro categorias: Tipos de utilização, formação docente, planejamento e observação das aulas.

\subsection{Tipos de Utilização: Agendamento e Projetos}

Durante o período de coleta de dados, a escola não estava desenvolvendo nenhum projeto, mas os agendamentos das atividades estavam acontecendo semanalmente. O professor do LIE relatou que costuma insistir com os professores de sala de aula para utilizarem o laboratório.

Segundo o professor do LIE, as aulas não costumam acontecer de forma espontânea, mas ele consegue levar os professores e suas turmas ao LIE. Além disso, tenta envolvê-los com atividades interessantes para que os professores de sala se sintam estimulados a utilizar com maior frequência o laboratório. Ele ainda informa que a turma de alunos só entra no laboratório de informática com a presença do seu professor que deverá estar à frente da aula, porém, assessorado pelo professor do LIE. Contudo, observamos que o professor de sala de aula fica, presencialmente, no laboratório, mas não consegue fazer a mediação da aula nem tirar dúvidas simples de uso de nenhum dos recursos utilizados.

Convém ressaltar que pouco depois desta pesquisa, o professor do LIE foi remanejado para sala de aula, o que fez com que este LIE, em específico, deixasse de ser utilizado pelos demais professores investigados, tendo em vista que os professores de sala de aula não se sentiam preparados para propor e medias aulas com as TDIC.

\subsection{Formações Docentes}

O professor do LIE trabalhava a 8 anos em laboratório de Informática, mas não possui formação específica em Informática Educativa. No momento da pesquisa encontrava-se fazendo especialização em Sistemas e Mídias Digitais pela Universidade Federal do Ceará. O professor comentou a necessidade de fazer alguns cursos para auxiliar sua prática, como por exemplo, o curso de Linux Educacional, que era ofertado pelo Prefeitura Municipal de Fortaleza, mas que pela dificuldade de liberação da escola ainda não pôde cursá-lo. O Centro de Formação e Assistência aos Profissionais da Rede Municipal de Ensino em Fortaleza, a Academia do Professor Darcy Ribeiro, é um espaço vinculado à Secretaria Municipal da Educação (SME). 
Apesar do tempo de experiência que o professor possui, nunca ofereceu nenhuma formação para o uso da Informática Educativa na escola. Ele relatou que sempre está à disposição dos professores de sala de aula para ajudar quando necessário e diz que "O máximo que fazemos é trazer o professor para utilizar o computador aqui no laboratório, estamos abertos e esse espaço também é deles" (Informação verbal do PL).

Todos os PS possuem computador e o utilizam com diversas finalidades como: Busca de informações, enviar e receber e-mail, preparar provas com o auxílio de editor de texto, consulta bancária e para comunicação com parentes distantes e redes sociais.

Apesar de todos já terem levado os seus alunos para o LIE da escola, responderam que não conhecem recursos suficientes e não possuem domínio de alguns programas específicos que permitisse que eles preparassem ou escolhessem os recursos a serem utilizados em sua aula. Todos preferem que o PL escolha o material a ser utilizado em suas aulas, pois confiam no trabalho desse professor.

Os PS fizeram diversos comentários, durante a entrevista, em relação ao uso do computador: "É muito bom usar o computador, pois é que nem televisão, tem muita coisa! Mas você tem que saber o que é bom ou o que não é..." (Informação verbal PS2). Esse comentário foi feito pelo professor ao afirmar que devido a quantidade de informações que se tem na rede é importante cautela na escolha do que vai ser utilizado, ou seja, tem que saber procurar e selecionar.

Os entrevistados afirmaram que acreditam no potencial pedagógico do computador: "Acredito na informática, pois é só ver que os alunos estão conseguindo fazer as atividades. A maioria desses alunos não faz nenhuma tarefa em sala de aula, mas chega ao LIE fazem as atividades, se concentram.” (Informação verbal PS3).

Dos cinco professores entrevistados, dois deles verbalizaram o interesse em fazer um curso de formação, de forma que aprimorasse o conhecimento que eles possuem, no entanto, os outros três disseram que não seria necessário, pois o professor do LIE poderia ajudá-los na escolha desses materiais.

\subsection{Planejamentos das atividades no LIE}

O professor de sala de aula faz seu planejamento, entrega para o professor do LIE que faz a sugestão de vídeos, jogos, sites ou slides para a aula. Na escola existia dois planejamentos: os dos professores de sala de aula e o do professor do LIE.

O planejamento pedagógico dos PS, antes da pandemia, era realizado durante os sábados, porém, devido a reivindicações, desses professores, tem sido realizado durante a semana, de segunda à sexta. Essa medida provocou alguns problemas na rotina escolar, pois para que esse professor possa planejar, tem sido necessário o remanejamento de suas turmas para espaços como quadra, biblioteca e laboratório de informática, pois as crianças não podem ser liberadas para voltar para casa. Essa atitude tem gerado problemas, pois muitas vezes os alunos vão ao LIE sem atividade definida, ou seja, só para preencher o tempo.

O planejamento das atividades no laboratório é semanal, acontecendo todas as sextas-feiras. Segundo o professor do LIE, em caso de necessidade, isto é, se for necessário o laboratório nas sextas ele se organizar para que seja possível realizar a aula planejada. Contudo, durante todos os dias que estivemos na escola para fazer o acompanhamento, observamos que as aulas não eram agendadas para esse dia.

Detectamos a falta de tempo para o planejamento como uma dificuldade. Seria adequado que os professores de sala de aula e do LIE pudessem escolher os recursos digitais a serem utilizados durante as aulas, em conjunto, pois, desta forma, tornaria o LIE uma extensão da sala de aula, integrando o uso das tecnologias digitais às atividades curriculares. Contudo, os professores de sala de aula realizam o seu planejamento em dias e horários diferentes que o professor do LIE.

Dessa forma, os PS têm dificuldade em fazer o planejamento de uma aula com o uso de tecnologia, pois na maioria das vezes, não conhecem nenhum recurso digital. Assim, o professor de sala de aula planeja, mas que escolhe os recursos é o 
professor do LIE. A partir dessa prática percebemos que o PS chega "perdido" ao laboratório, pois não conhece o material e não consegue mediar a utilização do recurso com sua turma. Em alguns casos, verificamos que a escolha do recurso pelo professor do LIE não foi adequada para o nível cognitivo da turma, o que se justifica pelo seu desconhecimento das dificuldades e potencialidades que as crianças de cada turma possuem.

Isso ficou ainda mais evidente durante a pandemia, pois além das dificuldades em planejar, os professores de Sala de aula (PS) também demonstraram dificuldades em utilizar ferramentas de comunicação como o Google Meet e o Whatsapp para a realização de atividades síncronas e assíncronas, respectivamente.

\subsection{Observações das aulas}

Durante as observações das cinco aulas presenciais, verificamos muitas das dificuldades levantadas pelo professor do LIE.

No início de cada aula era solicitado o planejamento realizado pelo professor de sala de aula, no entanto, em todas as aulas observadas esse planejamento não estava pronto, sendo preenchido no decorrer da aula, à medida que as coisas iam acontecendo. As aulas eram agendadas e os conteúdos definidos pelo PS, no entanto, o professor do LIE era quem escolhia todos os recursos digitais utilizados durante a aula. Isso foi constatado através de informação verbal do professor do LIE que elencou esse problema como uma das dificuldades encontradas e foi constatado durante as observações das aulas.

Apesar da presença do professor de sala de aula em quase todas as aulas, a aula é totalmente comandada pelo professor do LIE, que explica a atividade de acordo com o conteúdo a ser trabalhado (Português e Matemática). O professor de sala de aula tira dúvidas pontuais e individuais durante o desenvolvimento da atividade.

Enquanto o professor do LIE apresenta a atividade às crianças, os professores de sala de aula ficam sentados a observar a aula. Depois de entrevistarmos o professor de sala de aula, sobre o conhecimento inicial do jogo, ele nos informou que nunca havia utilizado nenhuma dessas atividades propostas pelo professor do LIE. Isso demonstra que o professor de sala de aula não participa da seleção dos recursos e que mesmo depois de escolhido o material a ser utilizado ele não se prepara para as aulas no LIE.

As aulas no laboratório eram sempre com o mesmo formato e por muitas vezes utilizavam o mesmo site e em alguns casos a mesma atividade, como podemos observar no Quadro 2.

Quadro 2 - Caracterização do uso pelos professores de sala de aula pesquisados: conteúdos trabalhados, ano e recursos utilizados.

\begin{tabular}{|c|c|c|c|}
\hline Sujeitos & $\begin{array}{l}\text { Conteúdos } \\
\text { trabalhados }\end{array}$ & $\begin{array}{c}\text { ano em } \\
\text { que atua }\end{array}$ & Recursos utilizados \\
\hline PS1 & Multiplicação & $4^{\circ}$ Ano $\mathrm{C}$ & 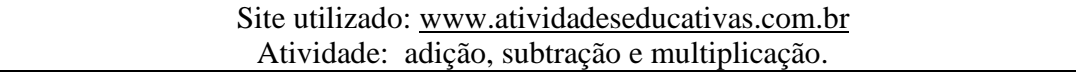 \\
\hline PS2 & $\begin{array}{l}\text { Alfabeto, treino } \\
\text { ortográfico, formação } \\
\text { de palavras }\end{array}$ & $2^{\circ}$ Ano B & Atividades desenvolvidas pelo professor do LIE com a utilização do "Calc". \\
\hline PS3 & Adição & $2^{\circ}$ Ano $\mathrm{C}$ & $\begin{array}{l}\text { Site utilizado: } \frac{\text { www.atividadeseducativas.com.br }}{\text { Foram usadas } 4 \text { atividades: Tabela da adição, pinguim, o patinho feio e aprendendo a }} \\
\text { contar }\end{array}$ \\
\hline PS4 & Operações matemáticas & $3^{\circ}$ Ano C & $\begin{array}{c}\text { Site utilizado: www.atividadeseducativas.com.br } \\
\text { Atividade: adição, subtração e multiplicação. }\end{array}$ \\
\hline PS2 & $\begin{array}{c}\text { Formação de frases } \\
\text { e palavras }\end{array}$ & $2^{\circ}$ Ano B & $\begin{array}{l}\text { Atividades desenvolvidas pelo professor do LIE com a utilização do "Calc", Site } \\
\text { utilizado: } \frac{\text { www.atividadeseducativas.com.br, atividades: }}{\text { Nome dos alimentos e escola games. }}\end{array}$ \\
\hline PS5 & As quatro operações & $5^{\circ}$ Ano A & $\begin{array}{l}\text { Site utilizado: } \underline{w w w . a t i v i d a d e s e d u c a t i v a s . c o m . b r ~} \\
\text { Atividade: adição, subtração, multiplicação e divisão. }\end{array}$ \\
\hline
\end{tabular}

Fonte: Autores, a partir dos dados coletados. 
A observação das aulas e a análise do material utilizado, nos permite afirmar o uso das TDIC de forma instrucionista, pois, em todos os casos observados, caracterizam-se por uma aprendizagem através da memorização e transmissão de conteúdo.

Dentre os Recursos Educacionais Digitais utilizados (RED), verifica-se pouca interatividade, ou seja, o aluno somente acompanha um conteúdo e posteriormente realiza testes e exercícios. Esse tipo de atividade não estimula o pensamento e a reflexão sobre os conteúdos propostos (Castro, 2016).

Todas as atividades realizadas e observadas possuíam um caráter extremamente tradicional e que reproduzia o que comumente era feito na sala de aula. Como nos exemplos das figuras 1 e 2 .

Figura 1 - A atividade (TABELA DA ADIÇÃO), turma $2^{\circ} \mathrm{C}$. Reprodução do que é feito em sala de aula, exercício de tabuada.

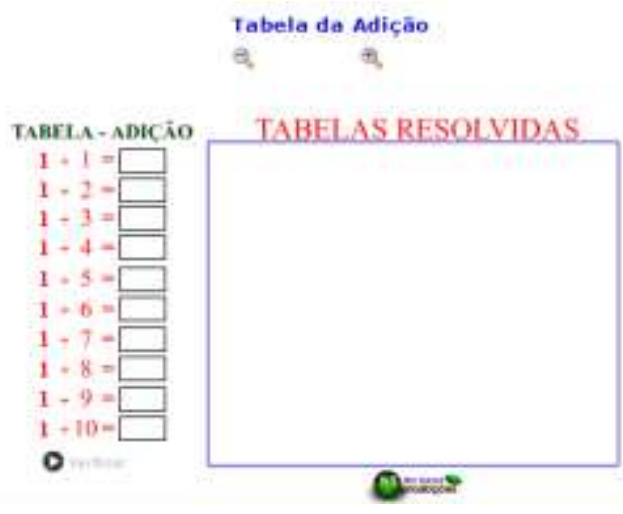

Fonte: Autores.
Figura 2. $-\mathrm{A}$ atividade (PINGUIM), turma $2^{\circ} \mathrm{C}$. Colorir as partes do desenho de acordo com as operações e as cores da paleta de tinta.

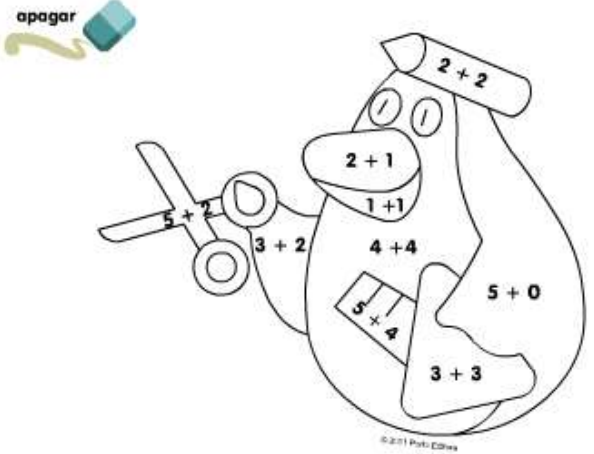

Fonte: Autores.

Algumas das atividades, apesar de possuírem características tradicionais, apresentam algum diferencial, como é o caso na Figura 3, em que é utilizado um sistema de representação diferente da numérica, representação icônica. Na representação icônica as quantidades e relações são representadas por figuras.

Na Figura 4, a atividade possui o recurso de animação. Esse diferencial tornou a atividade mais atrativa, fazendo com que fosse a escolhida como predileta da turma. Castro (2016) explica que o uso do RED não deve basear-se apenas na motivação ou interesse dos alunos, mas é preciso considerar o potencial pedagógico que cada RED apresenta para atingir os objetivos da aula. Nesse sentido, materiais com Múltiplas representações costumam facilitar o desenvolvimento conceitual, mas isso não quer dizer que garantam a aprendizagem (Castro, 2016; Castro \&Castro-Filho, 2020). 
Figura 3 - A atividade (O PATINHO FEIO), turma $2^{\circ}$. C. Figura 4 - Atividade Aprendendo a contar, turma $2^{\circ}$ C

Representação icônica e numérica.

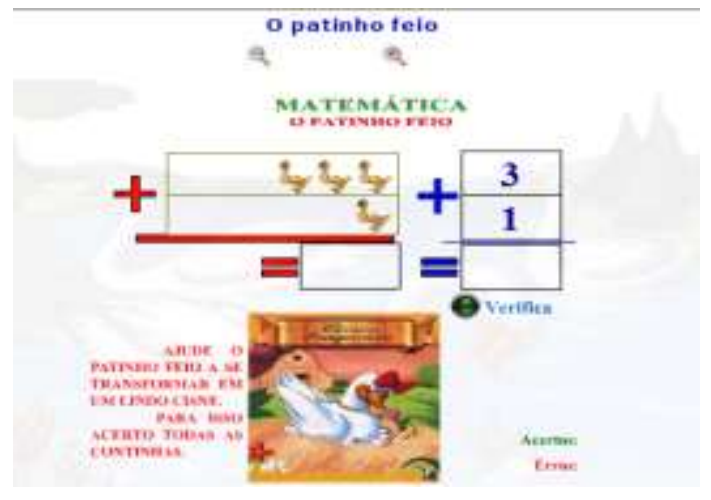

Fonte: Autores.
Animação e contagem.

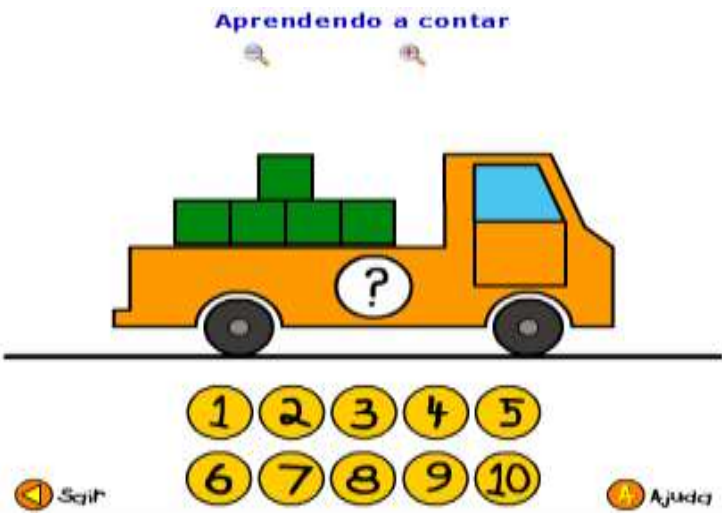

Fonte: Autores.

Para as atividades de Português, o professor do LIE geralmente preparava as aulas no "calc" (programa de planilha eletrônica - software livre). As aulas observadas eram referentes a formação de palavras e de frases. As atividades utilizadas simplesmente repetiam o que os alunos faziam em sala de aula, o que poderia ser feito com o uso de lápis e papel.

Os alunos começavam as atividades extremamente concentrados e interessados, porém, com o passar do tempo começam a ficar inquietos, a conversar e a dispersar durante a atividade. Esta situação serve de reflexão sobre o uso de RED nas escolas, pois a tecnologia não deve servir apenas como entretenimento e motivação, pois, com o tempo, deixa de ser novidade e pode passar a ser chata e enfadonha. Fato semelhante foi contatado em projeto realizado por Castro (2012), fazendo com que a pesquisadora tivesse que replanejar a proposta de uso de RED nas aulas de Matemática.

Como muitos alunos terminaram rapidamente, o professor do LIE começou a colocar outras atividades. Alguns alunos chegaram a fazer cerca de 4 atividades diferentes, com as mesmas características das iniciais. Isso aconteceu com duas turmas, uma de Matemática e a outra de Português. A partir dessas observações, podemos perceber a necessidade de (re) pensar o planejamento.

Durante as observações, nos deparamos com alguns alunos com necessidades especiais, como: baixa visão e surdez. A inserção desses alunos no laboratório é muito difícil, pois faltam equipamentos, programas e formação para essa inserção e consequentemente, adaptação. Os alunos com baixa visão ficavam com o rosto grudado na tela do computador, mesmo assim tinham dificuldade em visualizar a atividade. A aluna surda ainda estava aprendendo libras, mas não havia nenhum profissional na escola que soubesse. Durante a aula a maior dificuldade foi a de comunicação, pois era difícil explicar para a criança o que deveria ser feito. Ela estava bastante perdida nas atividades e apresentava diversas dificuldades.

Dentro dos aspectos observados, apresentaremos, a seguir, as considerações finais, incluindo uma reflexão sobre o uso da tecnologia na escola e a pesquisa das expectativas de possíveis trabalhos a partir do estudo realizado.

\section{Considerações Finais: Dificuldades e Desafios para a Prática Pedagógica}

Essa pesquisa possibilitou conhecer a prática pedagógica em um Laboratório de Informática Educativa de uma escola pública de Fortaleza, antes da pandemia causada pelo Novo Coronavírus. Para isso, observamos as práticas que aconteciam por meio dos agendamentos e planejamentos. Os resultados apontam para a necessidade de um planejamento racionalizado e em conjunto com os professores, a necessidade de formação continuada, com a participação de comunidades de aprendizagem que privilegie a produção de conhecimento. 
Os planejamentos realizados na escola são fragmentados, realizados de forma pontual e em alguns casos são feitos apenas para cumprir um "protocolo" sem uma funcionalidade definida. Não é disponibilizado pela escola momentos para que os professores possam interagir e escolher coletivamente os recursos que serão utilizados na aula no LIE. Esse momento de construção e interação entre os professores é extremamente importante para a escolha dos recursos a serem utilizados que deverão possuir objetivos pedagógicos e, desse modo, favorecerão a tecnologia digital no cotidiano escolar.

Apesar dos professores de sala de aula utilizarem as TDIC na sua vida cotidiana, possuem dificuldade em encontrar recursos digitais utilizando um critério metodológico, preparando atividades que favoreçam o aprendizado do aluno e a interação com o computador. Por esse motivo, a utilização das tecnologias educacionais na prática docente é limitada a reproduzir práticas tradicionais, como observado em todas as aulas.

Para que todo o potencial pedagógico desses materiais digitais seja explorado, o sujeito deverá possuir todo o domínio da técnica que envolve a manipulação destes recursos e criticidade na seleção, avaliação e utilização dos mesmos, sobretudo em função do crescente surgimento de novos formatos tecnológicos. Dentro dessa perspectiva é necessário investimento na formação continuada para professores, visando preencher as lacunas pedagógicas provenientes de sua formação inicial, de forma que os incentive a produção de conhecimento. Contudo, esta formação deve apoiar-se numa perspectiva crítica, que instrumentalize o professor, no tocante a utilização das tecnologias como ferramentas pedagógicas (Albuquerque, Fernandes \& Castro-Filho, 2010; Almeida, Lopes \& Braga, 2020).

Se políticas públicas tivessem sido realizadas de forma mais efetiva, talvez, a prática pedagógica destes professores no contexto do Ensino Remoto Emergencial poderia ter sido diferente. Pesquisas futuras apontam para a necessidade de acompanhamento pedagógico para um apanhado qualitativo e quantitativo das práticas durante e pós-pandemia.

\section{Referências}

Albuquerque, A. M. C., Fernandes, A. C. A., \& Castro Filho, J. A. (2010). Integração da Tecnologia Educacional ao Currículo Escolar: uma Análise, a partir do Planejamento Pedagógico Implementado em Escolas Públicas. In: II Seminário Web Currículo, 2010, São Paulo. Integração de tecnologias na prática pedagógica e no currículo.

Almeida, A. C. F. de, Lopes, L. F. de O., \& Braga, C. B. (2020). Professores Inovadores: mudanças de paradigmas a partir das necessidades apresentadas pelos alunos. Research, Society and Development, 9(7), e576974428. https://doi.org/10.33448/rsd-v9i7.4428

Almeida, M. E. B. \& Valente, J. A. (2016) Políticas de tecnologia na Educação Brasileira: histórico, lições aprendidas e recomendações. In: Centro de Inovação para a educação brasileira.

Almeida, F. J., Almeida, S. C. D. \& Fernades-Júnior, A. M. (2018) Cultura digital na escola: um estudo a partir dos relatórios de Políticas Públicas no Brasil. Rev. Diálogo Educ., 18(58), 603-623.

Castro, J, B. de (2012) A utilização de objetos de aprendizagem para a construção e compreensão de gráficos estatísticos. 2012. Dissertação (Mestrado em Educação) - Programa de Pós-graduação em Educação Brasileira, Universidade Federal do Ceará, Fortaleza-CE.

Castro, J. B. de (2016) Construção do conceito de covariação por estudantes do ensino fundamental em ambientes de múltiplas representações com suporte das tecnologias digitais. 2016. 275f. Tese (Doutorado) - Programa de Pós-graduação em Educação Brasileira, Universidade Federal do Ceará, Fortaleza-CE.

Castro, J. B. de \& Castro-Filho, J. A. (2012) Projeto um mundo de informações: integração de tecnologias digitais ao currículo escolar. Congresso Brasileiro de Informática na Educação, 1, 2012, Rio de Janeiro. Anais..., Rio de Janeiro: SBC, 2012.

Castro, J. B. de, \& Castro Filho, J. A. de. (2020). Projeto Pensar, Conectar e Fazer: o uso das Tecnologias Digitais para a aprendizagem da Proporcionalidade. Interfaces Científicas Educação, 9(2), 95-109. Disponível em: https://doi.org/10.17564/2316-3828.2020v9n2p95-109

Coll, C., Mauri, T. \& Onrubia,T. (2010). A incorporação das tecnologias da informação e da comunicação na educação: do projeto técnico-pedagógico às práticas de uso. In: Coll, C., Monero, C. e cols. Psicologia da Educação Virtual. Aprender e Ensinar com as Novas Tecnologias da Informação e Comunicação. Trad. Naila Freitas. Artmed, 2010. p.66 a 93.

Fagundes, L, Basso, M., Nevado, R., Bitencourt, J. \& Menezes, C. A. (2005) Um Ambiente Virtual para apoio ao Desenvolvimento de Projetos de Aprendizagem. SBIE2005.

Fusari, J.C. (1989) O papel do planejamento escolar, subsídios para ação-reflexão. COGESP.

Kalinke, M. A., \& Motta, M. S. (2019). Objetos de Aprendizagem: pesquisas e possibilidades na Educação Matemática. Ed. Life Editora. 
Research, Society and Development, v. 10, n. 16, e32101623269, 2021

(CC BY 4.0) | ISSN 2525-3409 | DOI: http://dx.doi.org/10.33448/rsd-v10i16.23269

Kenski, V. M. (2007) Educação e tecnologias: o novo ritmo da informação. Papirus.

Libâneo, J.C. (1992) Didática. Cortez.

Moran, J. M. (2015) Mudando a educação com metodologias ativas. [Coleção Mídias Contemporâneas. Convergências Midiáticas, Educação e Cidadania: aproximações jovens. Vol. II] Carlos Alberto de Souza e Ofelia Elisa Torres Morales (orgs.). PG: Foca Foto-PROEX/UEPG. http://www2.eca.usp.br/moran/wp-content/uploads/2013/12/mudando_moran.pdf

Papert, S. (2008) A máquina das crianças: repensando a escola na era da informática.: Artmed.

Prain, V. \& Waldrip, B. (2006) An exploratory study of teachers and students use ofmulti-modal representations of concepts in primary science. International Journal of Science Education, 28(15), 1843-1866.

Simião, L.\& Reali, A. (2002) O uso do computador, conhecimento para o ensino e a aprendizagem profissional da docência. Edufscar/Inep.

Triviños A. N. S. (1995) Introdução à pesquisa em ciências sociais: a pesquisa qualitativa em educação. Atlas.

Valente, J. A. \& Almeida, F. A. (1997) Visão Analítica da informática na educação no Brasil: A questão da formação do professor. Revista Brasileira de Informática na Educação.

Veiga, I. P. A. (1992). A prática pedagógica do professor de Didática”. 2Papirus. 